\title{
Theory and Application of Drilling Drainage Radius Determination Based on Drill Gas Flow Method
}

\author{
Zhu Ying ${ }^{1, a}$, Dai Linchao ${ }^{2,3}$, Wang Kai ${ }^{2,3}$ \\ ${ }^{1}$ Kunming Coal Research Institute, Kunming 650041, China; \\ ${ }^{2}$ National Key Laboratory of Gas Disaster Detecting, Preventing and Emergency Controlling, \\ Chongqing 400037, China; \\ ${ }^{3}$ Chongqing Research Institute Co.,Ltd. of China Coal Technology and Engineering Group, \\ Chongqing 400037, China. \\ a651246656@qq.com
}

Keywords: Drill gas flow method, Drilling drainage radius, Gas pumping rate

\begin{abstract}
In order to determine the drilling gas drainage radius, several different spacing drilling group were set up, and the relationship between drill pumping rate and the drainage time was solved through the relationships between drill gas flow and drainage time. Then on the basis of objective standards in line with drainage index for judging the pre-pumping rate, the drill group can be distinguished at the predetermined time to meet the target pre-drainage pumping rate, and the drilling gas drainage radius could be determined. By the field test study, it shows that the drill gas flow method is as practicable for measuring drainage radius.
\end{abstract}

\section{Introduction}

Drill seam gas is the most important measures to prevent the coal and gas outburst. Gas drainage radius is an important parameter for this measure, and whether it is reasonable or not directly relates to the effect and cost of conflict prevention. However, the determination of gas drainage radius is not yet formed a unified understanding in the practical applications, and with a certain amount of subjective empirical. Therefore, to determine a reasonable gas drainage radius parameters has an important practical significance to improve the drainage effect and quickly eliminate the outburst danger. Currently, there are three main methods for drainage radius field measurement investigation: gas pressure reduction method, drill gas flow method and gas content reduction method. But in the field measurement method, because of the gas pressure and gas content differ greatly in the different locations, the gas pressure reduction method and gas content reduction method have greater difficulty in the testing. But the drill gas flow method has simple operation, the effect of drainage can be verified, and it has been widely used. So in this paper, the drill gas flow method is used to in-depth research the drilling drainage radius.

\section{The principle of drill gas flow method to measure drainage radius}

Under the reasonable drainage radius, pre-drainage pumping drilling will cause drainage area to be drainage standards at the defined time. Drill gas flow method takes the relationship between the single-hole drilling gas drainage flow and the time to calculate the cumulative amount of gas drainage hole, then according to the total coal seam gas content, total drainage volume and the effective pumping rate, the effective drill spacing can be obtained at the different times.

The relationship between different pitches drill gas flow rate and time. In order to investigate the effect of drill gas, the initial drilling gas drainage volume $\left(q_{c 0}\right)$ and methane drainage attenuation coefficient $(\beta)$ were determined. To ensure the accuracy and representativeness of the measurement results, the test method by using the distance between holes packet was adopted. 
According to the gas drainage drilling mixed traffic, mixed concentration, drainage time and drilling length, the average gas drainage drilling scalar of per $100 \mathrm{~m}\left(q_{c t}\right)$ was converted, and combined with drilling drainage time(t), assay array $\left(\mathrm{t}, q_{c t}\right)$ was obtained. Based on the (t, $\left.q_{c t}\right)$, $q_{c 0}$ and $\beta$ can be determined by the regression analysis of formula(1).

$$
q_{c t}=q_{c 0} e^{-\beta t}
$$

Where, $q_{c 0}$ is the initial drilling gas drainage volume, $\mathrm{m}^{3} / \mathrm{min} \cdot \mathrm{hm}^{-1} \cdot q_{c t}$ is the average gas drainage drilling scalar of per $100 \mathrm{~m}, \mathrm{~m}^{3} / \mathrm{min} \cdot \mathrm{hm}^{-1} \cdot \beta$ is the drilling methane drainage attenuation coefficient, $\mathrm{d}^{-1} . \mathrm{t}$ is the drilling drainage time, $\mathrm{d}$.

The formula(1) is integrated, and then the total gas drainage drilling $Q_{c t}$ can be obtained at any time t.

$$
Q_{c t}=\int_{0}^{t} q_{c 0} e^{-\beta t}=\frac{1440 \cdot q_{c 0}\left(1-e^{-\beta t}\right)}{\beta}
$$

Where, $Q_{c t}$ is the total gas drainage drilling, $\mathrm{m}^{3} . Q_{c j}$ is the limit of drilling methane drainage when $t \rightarrow \infty, \mathrm{m}^{3}$.

The relationship between different spacing drill gas drainage rate and time.Gas drainage rate is the main indicators to measure the effect of coal seam gas drilling drainage. And it is to point to in a certain drainage time under a range of gas drilling out the amount and the ratio of the coal seam gas reserves within the range. It can use the formula(3) to calculate the gas drainage rate.

$$
\eta=100 \times Q_{\mathrm{ct}} /\left(L \cdot l \cdot M_{0} \cdot r \cdot W_{0}\right)
$$

Where, $\eta$ is the gas drainage rate,\%. $Q_{c t}$ is the drilling out pure gas quantity, $\mathrm{m}^{3} . L$ is the drilling control range, $\mathrm{m}$ (drilling arrangement spacing). $l$ is the drainage drill length, $\mathrm{m} . M_{0}$ is the average coal thickness, $\mathrm{m}$. $\mathrm{r}$ is the density of coal, $\mathrm{t} / \mathrm{m}^{3}$. $\mathrm{W}_{0}$ is the coal seam primitive gas content, $\mathrm{m}^{3} / \mathrm{t}$.

The determination of target pre-drainage pumping rate.According to the residual gas content and original gas content when gas drainage is up to standard, the target pre-drainage pumping rate can be calculated.

$$
\eta=\left(W_{0}-W_{r}\right) / W_{0}
$$

Where, $\eta$ is the drilling Gas pre-drainage rate, $\% . \mathrm{W}_{0}$ is the average original coal seam gas content, $\mathrm{m}^{3} / \mathrm{t}$. $\mathrm{W}_{\mathrm{r}}$ is the average residual coal seam gas content after drainage compliance, $\mathrm{m}^{3} / \mathrm{t}$.

Meanwhile, according to the Coal Mine Safety Regulation, it provides that after the pre-pumping coal seam gas, the coal seam gas pre-drainage is not more than 30\%.Combining with two indicators whichever is greater, the target pre-pumping rate can be obtained. And the drill group can be determined at the predetermined time to reach the target pre-drainage pumping rate, then the reasonable drainage radius can be got by using the distance between holes as the standard.

\section{The practical application of Drill gas flow method}

Test site selected in Panchengling mine's 150102 face, the strike length of the face is $1300 \mathrm{~m}$, the dip length is $150 \mathrm{~m}$. The average thickness of coal seam is about $5.66 \mathrm{~m}$, the dip angle is about $10^{\circ}$.

The arrangement of test drill. The parameters of drill in test section as follows: the drill diameter is $94 \mathrm{~mm}$, and the drill depth is $100 \mathrm{~m}$. Arranging four drill groups, and the drill distance is $2 \mathrm{~m}, 3 \mathrm{~m}$, $4 \mathrm{~m}$ and $5 \mathrm{~m}$, each group sets up five drills. Drill and drainage pipe layout diagram as shown in Fig.1.

Investigation results and analysis. In this four drainage drill groups, each group set up five drills, the flow field of the middle drainage drill in each group has closed to the actual gas flow field, can well represent the gas flow relationships over time in this spacing, fitting the relationship between gas flow and the time of the middle drill in each group, fitting curve as shown in Fig.2. 


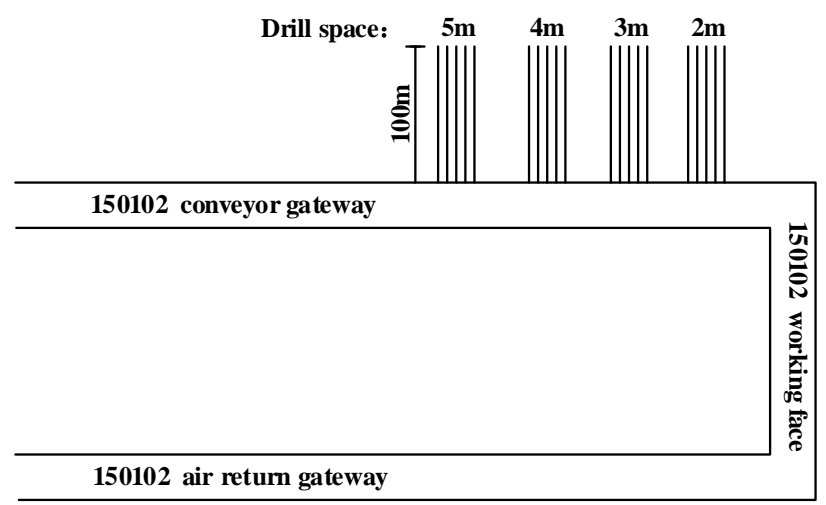

Fig.1 Drilling arrangement and drainage piping layout schematic

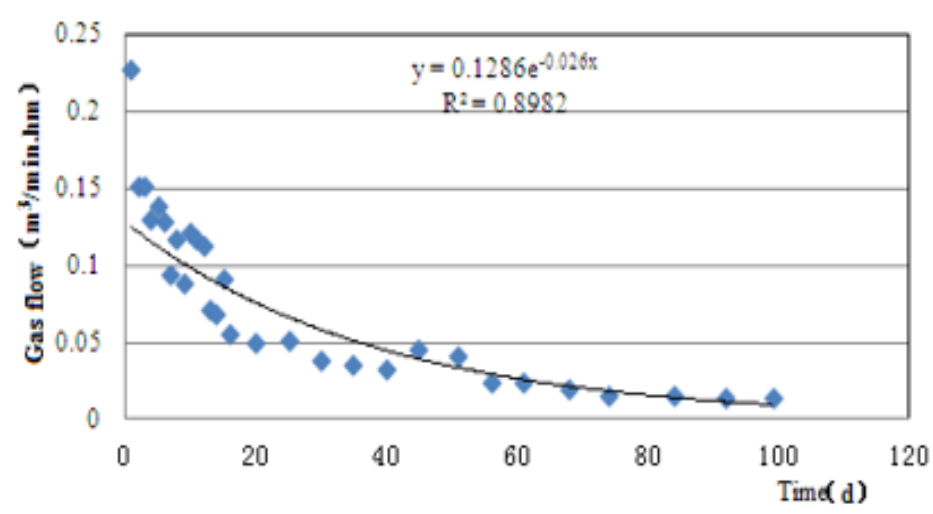

Fig.2 The relationship between gas flow and the drainage time under $2 \mathrm{~m}$ drill spaces

Table1 The relationship between drill flow, gas drainage flow of 100 meters, gas drainage rate and the drainage time under different drill spaces

\begin{tabular}{|c|c|c|c|}
\hline Drill space & Drill flow & $\begin{array}{c}\text { Gas drainage flow of } \\
100 \text { meters }\end{array}$ & Gas drainage rate \\
\hline $2 \mathrm{~m}$ & $q_{c t}=0.1286 \mathrm{e}^{-0.026 \mathrm{t}}$ & $Q_{c t}=7122.46\left(1-e^{-0.026 t}\right)$ & $\eta=43.83\left(1-e^{-0.026 t}\right)$ \\
\hline $3 \mathrm{~m}$ & $q_{c t}=0.1531 \mathrm{e}^{-0.025 \mathrm{t}}$ & $Q_{c t}=8818.56\left(1-e^{-0.025 t}\right)$ & $\eta=36.17\left(1-e^{-0.025 t}\right)$ \\
\hline $4 \mathrm{~m}$ & $q_{c t}=0.1657 \mathrm{e}^{-0.022 \mathrm{t}}$ & $Q_{c t}=10845.82\left(1-e^{-0.022 t}\right)$ & $\eta=33.37\left(1-e^{-0.022 t}\right)$ \\
\hline $5 \mathrm{~m}$ & $q_{c t}=0.1794 \mathrm{e}^{-0.02 \mathrm{t}}$ & $Q_{c t}=12916.80\left(1-e^{-0.02 t}\right)$ & $\eta=31.79\left(1-e^{-0.02 t}\right)$ \\
\hline
\end{tabular}

From the relationship between gas flow and drainage time under different drill spaces can be seen:gas drainage flow attenuate into negative exponential relationship with the increase of drainage time under different drill spaces, the longer drainage time, the smaller gas drainage flow; the smaller drainage drill space, the greater the attenuation coefficient of gas drainage flow, shows the smaller drill space, the faster gas content drop under the condition of the same gas content in the same area at the same time.

According to the formula(3), it can be received the relationship between gas drainage rate and drainage time within controlled range under different drill spacing as shown in Fig.3. From Fig.3, it shows that gas drainage rate exist a limit value under different drill spaces, increasing drainage time has no meaning when drainage rate increase a certain value.

Determination of effective drainage radius. Take the test site an average gas content of $9.97 \mathrm{~m}^{3} / \mathrm{t}$, and the remaining gas content of $2.07 \mathrm{~m}^{3} / \mathrm{t}$, according to the formula(4) can calculate the gas drainage rate $\eta=(9.97-7.2) / 9.97=27.78 \%$ when the coal seam gas drainage reach standard. At the same time, according to "coal mine safety regulations" regulation, coal seam gas drainage rate not greater than $30 \%$ after coal seam gas drainage. Therefore, the minimum gas drainage rate is $30 \%$ in work face of Panchengling mine.

According to above-mentioned analysis, it can get the function relation between gas drainage rate and drainage time under different spaces and gas drainage target rate $\eta$ is more than $30 \%$ when the 
coal seam drainage reach to standard, can be calculated under the condition of different spaces, in different drainage time corresponding to the coal seam gas drainage rate, the result see Table2.

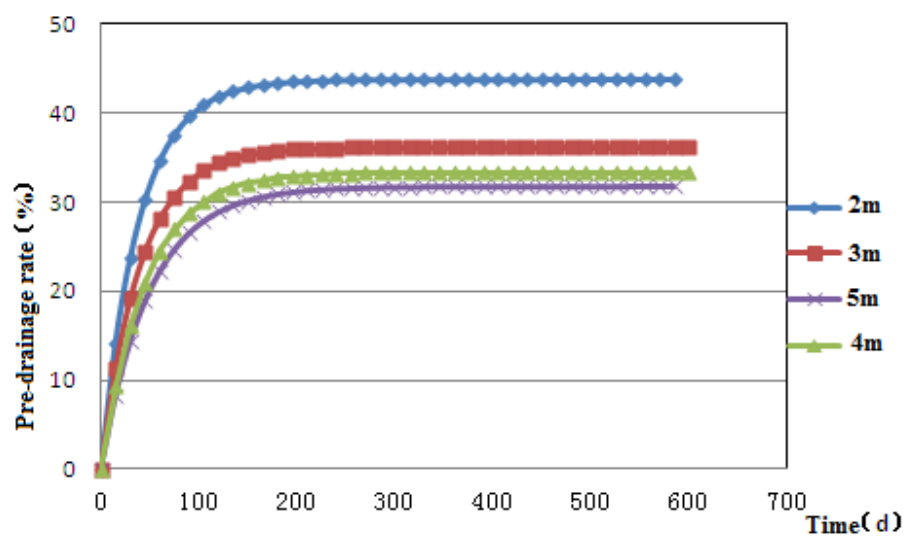

Fig.3 Gas drainage rate under different drill spaces

Table2 The relationship between gas drainage rate and drainage time under different spaces

\begin{tabular}{|c|c|c|c|c|}
\hline \multirow{2}{*}{$\begin{array}{c}\text { Drainage } \\
\text { period (day) }\end{array}$} & \multicolumn{4}{|c|}{ The drainage rate (\%) under different spacing } \\
\hline & $2 \mathrm{~m}$ & $3 \mathrm{~m}$ & $4 \mathrm{~m}$ & $5 \mathrm{~m}$ \\
\hline 30 & - & - & $\longrightarrow$ & $\longrightarrow$ \\
\hline 45 & 30.23 & - & - & 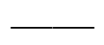 \\
\hline 60 & 34.62 & $\longrightarrow$ & $\longrightarrow$ & $\overline{-}$ \\
\hline 75 & 37.59 & 30.62 & $\longrightarrow$ & - \\
\hline 90 & 39.61 & 32.36 & $\overline{-}$ & 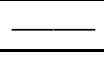 \\
\hline 105 & 40.97 & 33.55 & 30.06 & - \\
\hline 120 & 41.89 & 34.37 & 30.99 & 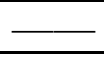 \\
\hline 135 & 42.52 & 34.93 & 31.66 & - \\
\hline 150 & 42.94 & 35.32 & 32.14 & 30.21 \\
\hline 165 & 43.23 & 35.59 & 32.49 & 30.62 \\
\hline 180 & 43.42 & 35.77 & 32.73 & 30.92 \\
\hline
\end{tabular}

According to Table2, drainage period of 60 days, $2 \mathrm{~m}$ drill space drainage reach to standard. And drainage period of 90 days, $2 \mathrm{~m}, 3 \mathrm{~m}$ drill space drainage reach to standard. Comprehensive comparison from project quantity, drainage time, determine the reasonable drainage time was 90 days, drill space is $3 \mathrm{~m}$. In a similar way, drainage period of 120 days, drill space is $4 \mathrm{~m}$.

\section{Conclusion}

(1)This paper describes the principle of drill gas flow method to measure the drainage radius.

(2)The drill gas flow method was used to on-site practice in Panchengling mine, and the corresponding drainage radius were determined in the pre-pumping period 60 days, 90 days, 120 days and 150 days .

(3)The drill gas flow method meets the needs of engineering practice, and it is as practicable for measuring drainage radius.

\section{References}

[1] T. Yu, P. Lu, J.H. Sun: Journal of Mining \& Safety Engineering, (2012) No.4, p.596-600.

[2] S.W. Li, Z.F. Zhang, D.Q. Xuan: Coal Science and Technology, (2014) No.4, p.43-45.

[3] G. Xu, S.G. Li, C. Liu: Coal Mining Technology, (2015) No.1, p.92-94,104. 